(1)

\title{
Pancreatic ductal adenocarcinoma in BRCA2 mutation carriers
}

\author{
Louis de Mestier1, Jean-Baptiste Danset², Cindy Neuzillet³, Vinciane Rebours', \\ Jérôme $\mathrm{Cros}^{4}$, Nadem Soufir 5 and Pascal Hammel 3
}

1Department of Gastroenterology and Pancreatology, Beaujon Hospital, Paris 7 University, APHP, Clichy, France 2Department of Hepato-Gastroenterology, European Georges-Pompidou Hospital, APHP, Paris, France ${ }^{3}$ Department of Digestive Oncology, Beaujon Hospital, Paris 7 University, APHP, Clichy, France 4Department of Pathology, Beaujon Hospital, Paris 7 University, APHP, Clichy, France

${ }^{5}$ Department of Genetics, Bichat Hospital, Paris 7 University, APHP, Clichy, France

\author{
Correspondence \\ should be addressed \\ to P Hammel \\ Email \\ pascal.hammel@aphp.fr
}

\begin{abstract}
Germline BRCA2 mutations are the first known cause of inherited (familial) pancreatic ductal adenocarcinoma (PDAC). This tumor is the third most frequent cancer in carriers of germline BRCA2 mutations, as it occurs in around $10 \%$ of BRCA2 families. PDAC is known as one of the most highly lethal cancers, mainly because of its chemoresistance and frequently late diagnosis. Based on recent developments in molecular biology, a subgroup of $B R C A 2$-associated PDAC has been created, allowing screening, early surgical treatment and personalized systemic treatment. BRCA2 germline mutation carriers who have $\geq 1$ first-degree relative, or $\geq 2$ blood relatives with PDAC, should undergo screening and regular follow-up based on magnetic resonance imaging and endoscopic ultrasound. The goal of screening is to detect early invasive PDAC and advanced precancerous lesions suitable for a stepwise surgical complete (RO) resection. Increasing evidence on the molecular role of the BRCA2 protein in the homologous recombination of DNA damages suggest that BRCA2-related PDAC are sensitive to agents causing DNA cross-linking damage, such as platinum salts, and treatments targeting rescue DNA repair pathways, such as poly(ADP-ribose) polymerase inhibitors that are currently under investigation.
\end{abstract}

\author{
Key Words \\ - BRCA2 \\ - pancreatic cancer \\ - screening \\ - treatment \\ - PARP inhibitors
}

\section{Introduction}

Pancreatic ductal adenocarcinoma (PDAC) is the eleventh most frequent cancer in the USA with 53,070 new cases per year, and it will become the second cause of cancer-related death by 2030 (Rahib et al. 2014, Ryan et al. 2014, Neuzillet et al. 2015, Siegel et al. 2016). The low 5-year survival rate (about $7 \%$ ) is due to its highly invasive progression, with tumors that are frequently non-resectable at initial diagnosis, a fibrotic, immunosuppressive and hypoxic microenvironment promoting tumor resistance to chemotherapy, and rapid clinical deterioration due to pain, systemic inflammation and cachexia. The main known risk factors for PDAC are cigarette smoking, diabetes mellitus, obesity, chronic pancreatitis and a family history of PDAC (Raimondi et al. 2009, Ryan et al. 2014, Neuzillet et al. 2015).

Familial PDAC is defined by the occurrence of PDAC in a pair of first-degree relatives and accounts for $10 \%$ of all cases of PDAC (Vincent et al. 2011, Ryan et al. 2014, Neuzillet et al. 2015). The risk of developing PDAC increases along with the number of first-degree relatives with familial PDAC, with a standardized incidence ratio of between 17 and 32 for subjects with $\geq 3$ first-degree relatives with PDAC (Klein et al. 2004, Brune et al. 2010). Moreover, relatives with familial PDAC harbor more

This paper forms part of a thematic review section on 20 Years of BRCA 1 and 2 The Guest Editors for this section were Kokichi Sugano and William Foulkes. 
precancerous pancreatic lesions and have a higher risk of extra-pancreatic tumors compared with patients with sporadic PDAC (Shi et al. 2009, Wang et al. 2009).

The identification of PDAC predisposition genes in patients with familial PDAC is highly important because it allows family members to undergo genetic testing, PDAC screening, earlier prophylactic resection of precancerous lesions and personalized therapy. Germline mutations have been described in BRCA2, BRCA1, p16/CDKN2A, PALB2, PRSS1, STK11, TP53, ATM and Lynch syndrome-associated genes (Klein 2012, Salo-Mullen et al. 2015, Zhen et al. 2015, Hu et al. 2016, Roberts et al. 2016). However, no germline mutations have been identified in up to $80-85 \%$ of cases of familial PDAC. BRCA2-related PDAC is a prototypical example of familial PDAC for cancer biology, screening strategy and personalized therapeutic opportunities. The aim of this paper is to comprehensively review the current knowledge about PDAC in BRCA2 mutation carriers.

\section{Epidemiological links between BRCA2 mutations and PDAC}

Germline BRCA2 mutations are inherited in an autosomal dominant fashion with incomplete penetrance and are associated with increased risks of breast and ovarian cancers and, to a lesser extent, prostate, colorectal and pancreatic cancers. About $10 \%$ of all BRCA2 families have at least one relative with PDAC (Kim et al. 2009). Mutation carriers have a three- to six-fold increased risk of developing PDAC compared with non-carriers (Luo et al. 2015). In two series of 173 and 139 BRCA2 families, the relative risk of PDAC was estimated to be 3.5 (95\% CI, 1.9-6.6) (Breast Cancer Linkage Consortium 1999) and 5.9 (95\% CI: 3.2-10) (van Asperen 2005), respectively. The relative risk of PDAC was 2.13 (95\% CI: 0.36-7.03) in a cohort of over 5,149 women with BRCA2 mutations (Iqbal et al. 2012). In these studies, the risk of PDAC in BRCA2 mutation carriers was higher in patients over 65 years old.

However, the prevalence of BRCA2 germline mutations in patients with apparently sporadic PDAC is $4-7 \%$ (Goggins et al. 1996, Ferrone et al. 2008, Holter et al. 2015, Zhen et al. 2015, Hu et al. 2016) compared with $0.2 \%$ in the Caucasian population (Anglian Breast Cancer Study Group 2000). However, these data are based on heterogeneous studies (Luo et al. 2015). It should be noted that the BRCA2 mutation rate was lower in series of unselected PDAC patients than in PDAC cell lines (Goggins et al. 1996, Ferrone et al. 2008).
Germline BRCA2 mutations are identified in $4-17 \%$ of families with familial PDAC and are the most common germline genetic alteration identified in this condition (Murphy et al. 2002, Hahn et al. 2003, Couch et al. 2007, Salo-Mullen et al. 2015, Zhen et al. 2015, Hu et al. 2016, Roberts et al. 2016). However, this rate varies depending on the definition of familial PDAC, i.e., the number of relatives affected to define a population at risk. Couch et al. (2007) reported a $4 \%$ prevalence of PDAC in families with two first- or second-degree relatives with PDAC and $10 \%$ in families with $\geq 3$ involved relatives. However, all BRCA2-related PDAC families are not affected with a family history of breast, ovarian and/or prostate cancers, and PDAC can result as the single family cancer in some families with $B R C A 2$ germline mutations, suggesting variable penetrance and phenotypic expression (Goggins et al. 1996, Couch et al. 2007, Klein 2012, Holter et al. 2015, Zhen et al. 2015). Germline BRCA2 mutations, particularly the founder 6174 delT mutation, are associated with $10-20 \%$ of unselected and apparently sporadic PDAC in the Jewish Ashkenazi population (Ozçelik et al. 1997, Ferrone et al. 2008, Lucas et al. 2013).

Patients with BRCA2-associated PDAC are younger than their counterparts with sporadic PDAC, with a median age difference of 7 years (63 vs 70years, respectively) in two large studies, but a similar sex ratio (Kim et al. 2009, Lucas et al. 2013). Other clinicopathological features were similar in both populations except for a personal and family history of cancer (Ferrone et al. 2008, Golan et al. 2014). The survival rate in patients with familial history of PDAC may be increased compared with that in those with sporadic PDAC, possibly due to increased chemosensitivity to platinum salts (see below) (Golan et al. 2014, Fogelman et al. 2015).

Somatic mutations in genes involved in DNA repair, including $B R C A 2$, but also BRCA1, PALB2 or ATM, have been described in 10-15\% of all sporadic PDAC (Waddell et al. 2015, Bailey et al. 2016). Indeed, a recent study on PDAC whole genome sequencing classified PDAC into 'stable', 'locally rearranged', 'scattered' and 'unstable' subtypes based on the variations in chromosomal structures (Waddell et al. 2015). The 'unstable' subtype represented $14 \%$ of all PDAC and was characterized by a large number of structural variation events, suggesting defects in DNA repair pathways related to a 'BRCA mutational signature' (Waddell et al. 2015, Bailey et al. 2016).

Finally, the histogeneses of 'conventional' PDAC and intraductal papillary mucinous neoplasms (IPMN) are

Published by Bioscientifica Ltd 
different, with specific genomic signatures (Bailey et al. 2016). This might explain why the prevalence of $B R C A 2$ germline mutations in patients with 'conventional' PDAC or PDAC derived from IPMN are different, for example, 19 vs $29 \%$, respectively, in the study of high-risk Ashkenazi individuals by Lucas et al. (2013).

\section{PDAC risk assessment and screening strategies in BRCA2 mutation carriers}

Pancreatic screening in high-risk patients such as BRCA2 mutation carriers has been proposed to reduce PDACrelated mortality. In 2012, the International Cancer of the Pancreas Screening (CAPS) Consortium published guidelines on the management of patients with increased risk for familial PDAC (Canto et al. 2013). The aim of screening is to detect and remove precancerous lesions such as multifocal high-grade pancreatic intraepithelial neoplasia (PanIN) lesions and IPMN with high-grade dysplasia (Shi et al. 2009, Matthaei et al. 2011, Lucas et al. 2013) in patients eligible for pancreatic surgery (Klapman \& Malafa 2008, Bartsch et al. 2016).

BRCA2 mutation carriers should be considered for PDAC screening if they have $\geq 1$ first-degree relative, or $\geq 2$ any degree relatives with PDAC (Canto et al. 2013). Iqbal et al. (2012) have reported a relative risk of 46.5 (95\% CI: 9.4-230) in developing PDAC in BRCA2 mutation carriers with a first-degree relative affected by PDAC compared with those without. Subjects with Jewish Ashkenazi ancestry and a family history of PDAC should also be considered for genetic counseling and testing for the founder BRCA2 gene mutation (6174delT), which is present in $1 \%$ of Ashkenazi Jewish individuals (Ferrone et al. 2008, Canto et al. 2013, Lucas et al. 2014).

The age to initiate screening in high-risk BRCA2 mutation carriers is a subject of debate. Certain authors recommend to begin screening at the age of 40 years, or 10years earlier than the youngest relative with PDAC (Ludwig et al. 2011, Canto et al. 2012). The CAPS consortium guidelines recommend to start screening at the age of 50years (Canto et al. 2013) because the incidence of PDAC appears to be low in younger subjects. This was confirmed in the study by Bartsch et al. (2016), in which high-risk individuals developing PDAC were not younger at the time of PDAC diagnosis than index cases, and with no significant lesions before the age of 50 years. Thus, although medico-economic studies are needed, screening before the age of 50 years may not be cost-effective in this setting (Ludwig et al. 2011, Canto et al. 2013, Bartsch et al. 2016). Finally, although tobacco consumption increases the risk of PDAC in subjects with familial PDAC history, there is no recommendation for earlier screening in smokers.

The most widely accepted tools for PDAC screening are endoscopic ultrasound (EUS) and magnetic resonance imaging (MRI) cholangiopancreaticography (Klapman \& Malafa 2008, Canto et al. 2013, Lu 2015, Bartsch et al. 2016). The prevalence of small, mostly cystic, pancreatic lesions was 42.6 and $33.3 \%$ by EUS and MRI, respectively, in the CAPS3 study (Canto et al. 2012). These rates are higher than those obtained with computed tomography (11\%). However, benign cystic lesions are frequent in the general population and can be misdiagnosed as malignant during EUS and/or MRI screening, leading to a risk of surgical overtreatment with potential morbidity and even mortality (Tanaka et al. 2012, Neuzillet et al. 2015). According to the 2012 Fukuoka consensus guidelines for sporadic pancreatic cystic lesions (Tanaka et al. 2012), the high-risk signs of malignancy include obstructive jaundice associated with cystic lesions of the head of the pancreas, enhancing solid component in cysts and a main pancreatic duct $>10 \mathrm{~mm}$. In patients without these signs, suggestive features must be searched for, i.e., cysts $>3 \mathrm{~cm}$, thickened/enhancing cyst walls, main duct size of 5-9 $\mathrm{mm}$, non-enhancing mural nodule, rapid change in size of the pancreatic duct with distal pancreatic atrophy and regional lymphadenopathy.

The follow-up of BRCA2 mutation carriers at a high risk of developing PDAC is based on a combination of EUS and MRI (Canto et al. 2013, Lu 2015). Repeated carcinoembryonic antigen and carbohydrate antigen 19.9 dosages have not been shown to be effective in detecting precancerous lesions, as they usually do not express these markers in serum (Langer et al. 2009). A 12-month follow-up interval is proposed in patients with no baseline pancreatic abnormalities. In case of non-suspicious cysts, the interval can be reduced to 6 months and to 3 months in case of newly detected undetermined solid lesions if upfront surgery is not indicated or in case of undetermined main pancreatic duct strictures. In addition, branch-duct IPMN without signs of malignancy should be followed up according to the Fukuoka consensus guidelines (Tanaka et al. 2012).

Nevertheless, studies on PDAC screening have reported a low prevalence of diagnosed lesions and there is no clear consensus on the precise definition of a 'significant' lesion (Langer et al. 2009, Ludwig et al. 2011, Canto et al. 2012, Lu 2015). Although pancreatic lesions were frequently detected $(42 \%)$ in the CAPS3 study, 5/225 patients underwent pancreatic surgical

Published by Bioscientifica Ltd. 
resection and only three of them had high-grade lesions (Canto et al. 2012). Similarly, in the study by Bartsch et al. (2016), pancreatic lesions were identified in $134 / 253$ patients, including $21(8.3 \%)$ who underwent surgical resection and only six (2.4\%) with malignant or high-grade lesions on the resected specimen. Similarly, in the German study, after an average 7-year screening period, 6/76 (7.9\%) patients underwent pancreatic surgical resection for suspicious lesions, including only one patient (1.3\%) with a high-grade lesion (Langer et al. 2009). A systematic review of nine studies on familial PDAC screening found that although the pancreatic tumor detection rate was 7.9-50\%, the PDAC detection rate was only $0-6.8 \%$, with no PDAC detected in $4 / 9$ studies. Finally, although a recent large European study highlighted the relevance of close follow-up in asymptomatic CDKN2A mutation carriers, it was less effective in other individuals with a family history of PDAC. In the latter group, the screening program resulted in pancreatic resection in $3 / 214$ patients for suspected PDAC $(1.4 \%$, including only one with a final diagnosis of PDAC) and in 13/214 patients because of suspected cystic precursor lesions $(6.1 \%$, including only four with high-grade lesions) (Vasen et al. 2016).

To summarize, a non-negligible number of mutation carriers undergo unnecessary surgery, i.e., have noncancerous lesions. In addition, pancreatic surgery carries significant morbidity and even mortality, and screening programs generate anxiety (Breitkopf et al. 2012). Thus, additional studies are needed to better define the highrisk groups that will benefit from screening programs. The diagnostic value of the current screening methods should be increased to improve the relevance of screening for familial PDAC. The goal of future research should be to establish reliable blood or urine biomarkers to develop a non-invasive, accurate and cost-effective method to detect PDAC precursor lesions in BRCA2 mutation carriers.

\section{Specific aspects of surgical management in BRCA2 mutation carriers with PDAC}

Pancreatic resection should be performed at high-volume specialized centers, as center volume correlates with surgical results and morbidity (Gooiker et al. 2014). Solid lesions detected on EUS or MRI (generally by both), particularly when they appear during systematic yearly screening, should be considered potentially malignant. A biopsy can be proposed in case of doubt and surgical resection should be considered whatever their size
(Canto et al. 2013). In contrast, prophylactic surgery is not recommended in high-risk BRCA2 mutation carriers without identifiable lesion because of potential morbidity and ill-defined benefit:risk ratio.

Most lesions discovered during screening are branch-duct IPMN, whose treatment depends on the risk of malignancy according to the Fukuoka consensus guidelines (Tanaka et al. 2012). In particular, surgical resection should be considered in the presence of cystrelated symptoms (obstructive jaundice and pancreatitis) or any other high-risk signs of malignancy. Conversely, in the absence of these signs but in the presence of suspicious features, surgical resection is not systematically recommended but should be considered in case of definite mural nodules, main duct features suggesting involvement and/or when cytology suggests malignancy (Tanaka et al. 2012). The usual cyst size threshold used to indicate surgery could probably be lowered in BRCA2 mutation carriers. Indeed, pathological analysis of surgically resected pancreatic specimens from BRCA2 mutation carriers with IPMN $<10 \mathrm{~mm}$ were found to have concomitant high-grade PanIN lesions, high-grade dysplasia and/or main duct involvement with IPMN (Canto et al. 2012, 2013).

Resection margins should be examined during the surgical intervention for IPMN of either the main or branch ducts. If high-grade PanIN are detected on resection margins, larger pancreatic resection should be considered to achieve R0 surgery, although this was not set out in the CAPS expert consensus (Canto et al. 2013). However, additional pancreatic resection should not be performed in the presence of low-grade PanIN on resection margins (Tanaka et al. 2012, Canto et al. 2013). Postoperatively, the presence of high-grade PanIN at a distance from the main lesion and determined by histopathological examination of the resected specimen is important, but this management is a subject of debate. In this situation, a total pancreatectomy may be considered, as there is a risk of second (and different) PDAC in these patients. In all cases, close and early imaging follow-up ( $<6$ months) should be performed in these patients (Canto et al. 2013). It is important to obtain an individual multidisciplinary assessment of the benefit:risk ratio of extensive pancreatic resection for each patient. Obviously, this strategy does not apply to patients with macroscopic invasive PDAC, in whom standard curative intent resection is recommended without additional pancreatic resection (Matthaei et al. 2011). 


\section{Pathophysiological pathways leading to the development of PDAC in BRCA2 mutation carriers: moving toward personalized treatment}

The causes of DNA replication errors include free oxygen radicals generated by the cellular metabolism, ultraviolet light, radiation and chemicals. Homologous recombination (HR) is a high-fidelity repair system of double-strand DNA breaks and DNA cross-linking damages induced by DNA-damaging agents. The BRCA1 and BRCA2 proteins are key regulators of the HR system and are localized in the nucleus in response to the formation of RAD51 foci, following DNA damage. BRCA1 plays a central role in identifying double-strand DNA breaks and in initiating the process of DNA repair by recruiting the HR machinery (Moynahan et al. 2001, Lee et al. 2014, Fradet-Turcotte et al. 2016). BRCA2 regulates the formation of RAD51 nucleoprotein filaments and the strand invasion by the single-strand DNA used for HR repair (Thorslund \& West 2007, Holloman 2011, Lee 2014, Fradet-Turcotte et al. 2016). Thus, BRCA2 loss-of-function prevents the HR-mediated double-strand break repair, accounting for high levels of spontaneous chromosomal aberrations and genetic instability.

Following the two-hit Knudson model in BRCA2 germline mutation carriers, PDAC contains a loss of heterozygosity in the BRCA2 gene due to second allele damage. The loss of functional BRCA2 gene in tumor tissue impairs HR function. For example, Lucas et al. (2013) reported a loss of heterozygosity in 50\% of BRCA1associated and $75 \%$ of $B R C A 2$-associated PDAC in a series of 39 BRCA1/2 mutation carriers with Jewish Ashkenazi ancestry. In addition, micro-dissection of PDAC samples from IPMN in one patient revealed partial and complete loss of heterozygosity in IPMN and PDAC lesions, respectively. As IPMN may progress to PDAC, biallelic loss of BRCA is a plausible contributor to PDAC formation (Fam 2014).

Multiple somatic events occur in PDAC carcinogenesis, such as p53 and SMAD4 inactivation (Lucas et al. 2013, Neuzillet et al. 2014). Indeed, chromosome breaks due to incomplete or inadequate DNA repair normally activate p53-dependent checkpoint controls and/or apoptosis to prevent tumor formation. PDAC murine models suggest that TP53 mutations may occur before BRCA1/2 loss of heterozygosity in PDAC oncogenesis and that monoallelic $B R C A 1 / 2$ loss-of-function could promote TP53 and KRASdriven tumorigenesis (Skoulidis et al. 2010, Rowley et al. 2011, Fam 2014).

\section{Use of cross-linking cytotoxic agents in BRCA2 mutation carriers with PDAC}

Therapies exploiting the inability of $B R C A 2$-associated tumor cells to repair double-strand DNA breaks could improve the outcome in these patients compared with those with BRCA2 wild-type tumors. DNA-targeting cytotoxic agents generating DNA strand breaks include platinum salts, topoisomerase inhibitors, alkylating agents and mitomycin C. Intra- and inter-strand platinum-DNA cross-links induce double-strand DNA break damage. DNA reparation requires functioning BRCA2 (Thompson 2005). BRCA2-mutated cancers lack HR repair, thus platinuminduced double-strand breaks are not fixed, and further genomic damage goes on, leading to cell death (Dhillon et al. 2016).

Cancerous tumors of BRCA2 mutation carriers have a peculiar sensitivity to platinum salts (and other DNA-damaging agents), and prolonged survival can be expected (Waddell et al. 2015). This was first suggested in studies reporting overall survival that was nearly double than that expected in patients with $B R C A$-associated epithelial ovarian cancers who received platinum-based combination chemotherapies or pegylated liposomal doxorubicin (Gallagher et al. 2011, Kaye et al. 2012). Similarly, a significant response rate $(9 / 10)$ was obtained with neoadjuvant cisplatin in BRCA1 mutation carriers with breast cancer, a rate that is clearly higher than that, 15-34\%, reported in previous studies using taxanes and anthracycline combinations (Byrski et al. 2009).

In the above-mentioned PDAC genomic study by Waddell et al. (2015), the 'unstable' PDAC subtype associated with defects in DNA repair pathways was characterized by platinum salt sensitivity. Preclinical models using PDAC cell lines as well as patient-derived murine xenografts have shown that tumor BRCA2 deficiency was significantly associated with sensitivity to DNA cross-linking agents (such as platinum salts), as well as radiation therapy compared with BRCA2 proficiency (Porcelli et al. 2013, Andrei et al. 2015, Lohse et al. 2015). In addition to case reports (Sonnenblick et al. 2011), several retrospective case series have described marked efficacy of platinum salts in BRCA2 mutation carriers with advanced PDAC (Lowery et al. 2011, Golan et al. 2014, Luo et al. 2015, Vyas et al. 2015). In one study, median overall survival was 22 months vs 9 months in BRCA1/2 mutation carriers with stage III-IV PDAC who received platinum $(n=22)$ vs another chemotherapy $(n=21)$, respectively $(P<0.039)$ (Golan et al. 2014). Interestingly, Fogelman and colleagues (2015)

Published by Bioscientifica Ltd. 
reported that a familial history of PDAC was a marker of sensitivity to platinum in patients with PDAC. More precisely, overall survival was improved in those receiving first-line platinum therapy along with the number of relatives with pancreatic, ovarian and/or breast cancers, which was not the case with other first-line chemotherapies. Nevertheless, most BRCA2associated tumors in general, and PDAC in particular, become resistant to platinum salts over time. Secondary acquired intragenic $B R C A$ mutations that restore the protein function were reported in cases of primary or secondary resistance to cisplatin (Sakai et al. 2008).

\section{Development of PARP inhibitors for patients with BRCA2-associated PDAC}

In compensation for HR deficiency to BRCA2 loss-offunction, DNA repair mainly relies on base excision repair, which is a backup single-strand DNA break repair system. The limiting base excision repair enzyme is the poly(ADP-ribose) polymerase (PARP)1, which adds branched chains of poly(ADP-ribose) polymerase to damaged DNA and thus induces separation of histones from DNA to enable DNA repair. PARP1 identifies the site of DNA injury and recruits repair complexes involved in non-homologous end-joining activity, which is a lowfidelity alternative reparation mechanism (Lee et al. 2014). Hence, PARP1 activity is essential in HR-deficient BRCA2-mutated tumor cells.

Synthetic lethality is a phenomenon in which two non-lethal genetic mutations are innocuous when they occur individually, but result in cell death when combined. Based on this principle, PARP1/2 inhibitors (PARPi) have been developed to target tumor cells in $B R C A 1 / 2$ mutation carriers, in which loss-of-function of both HR and base excision repair leaves DNA doublestrand breaks unrepaired, leading to accumulation of DNA damage, genomic instability and ultimately cell death (Bryant et al. 2005, Farmer et al. 2005, Sandhu et al. 2010, Yap et al. 2011, Dhillon et al. 2016). Moreover, PARPi exert direct DNA toxicity by trapping PARP1 (and PARP2) at damaged DNA where the PARPDNA complexes are more cytotoxic than unrepaired single-strand DNA breaks themselves (Murai et al. 2012). These preclinical results have been confirmed in vivo, where BRCA2-deficient tumors showed hypersensitivity to PARPi therapy with significant tumor regression (Hay et al. 2009).

Clinically, patients with BRCA2 (and BRCA1) mutation-associated cancers have a marked sensitivity to
PARPi, as demonstrated for the first time by Fong et al. (2009) in a phase I tolerance study. In that study, 63\% of mutation carriers with breast, ovarian or prostate cancers who received olaparib were likely to have a clinical benefit based on a radiological and/or an objective biological response. This suggests that BRCA1/2 mutations are predictive genetic biomarkers of response to PARPi. This was confirmed in a multicenter phase II study in 298 patients with BRCA1/2 germline mutations, who received olaparib $400 \mathrm{mg}$ twice a day, resulting in tumor control in 64\% (tumor response rate: 26\%, stability: 42\%) (Kaufman et al. 2015). Several PARPi are under clinical development, alone or in combination therapy (Lee et al. 2014). The loss of the base excision repair capacity produced by PARPi has encouraged their combination with DNA-damaging agents, such as platinum salts, alkylating agents or radiation therapy.

PARPi have been shown to have relevant antitumor efficacy in BRCA1/2-associated advanced PDAC (Sandhu et al. 2010, Yap et al. 2011, Luo et al. 2015). Preclinical models have shown that tumor BRCA2 deficiency was significantly associated with sensitivity to PARPi (Andrei et al. 2015). A phase II study included 23 patients with advanced BRCA2-mutated PDAC who had previously received an average of two lines of chemotherapy (including platinum-based chemotherapy in 65\%) (Kaufman et al. 2015). Five patients (22\%) and eight patients (35\%) had an objective response and stable disease (disease control rate: 57\%) using olaparib, respectively, with a median response of 4.4 months. These results in a heavily pretreated advanced PDAC population are promising and support further evaluation of PARPi in BRCA1/2-associated PDAC.

Besides their potential use as a single agent, PARPi are promising in combination with cytotoxic chemotherapies classically used in PDAC. Following preclinical models suggesting the greater efficacy of gemcitabine combined with PARPi than alone (Jacob et al. 2007), there have been reports of a marked response to gemcitabine plus iniparib (Fogelman et al. 2011, Lowery et al. 2011). A phase I trial showed that this association was safe (except with doses $>600 \mathrm{mg} / \mathrm{m}^{2}$ of gemcitabine) in patients with PDAC, although only a few had BRCA1/2 germline mutations (Bendell et al. 2015). In that trial, a dose expansion phase including 15 patients who received olaparib $(100 \mathrm{mg})$ plus gemcitabine $\left(600 \mathrm{mg} / \mathrm{m}^{2}\right)$ showed that the overall response rate doubled without additional toxicity compared with seven patients who received gemcitabine alone.

Although these results are promising, most published studies are non-randomized, non-comparative,

Published by Bioscientifica Ltd 
retrospective, monocentric and limited in size. Moreover, most previous studies have been performed in the Ashkenazi Jewish population, which may limit extrapolation of the results to PDAC patients with different BRCA2 mutations (Luo et al. 2015). Phase II and phase III studies in larger size populations are currently ongoing to assess the efficacy and tolerance of PARPi such as olaparib, rucaparib, talazoparib and veliparib, alone or in combination with cytotoxic agents in patients with advanced PDAC (Table 1).

Safety data are now robust because thousands of patients have been treated with PARPi. The largest clinical experience to date was performed with olaparib monotherapy, which has been assessed in various malignancies. It is generally well tolerated at doses of 300-400 mg twice daily, and some patients were even able to continue for several years. Studies have reported manageable side effects including bone marrow toxicity, fatigue, headache, nausea and abdominal pain (Lee et al. 2014, Kaufman et al. 2015). Because of the potential increased toxicity in combination with DNA-targeting agents, the combination of olaparib with platinum salts may require reducing the dose of both drugs.

As with platinum salts, most BRCA-associated PDAC develop resistance to PARPi, often through the secondary development of intragenic BRCA2 mutations as well as $P A R P 1 / 2$ mutations that restore the protein function (Sakai et al. 2008). However, primary or acquired resistance to platinum is insufficient to predict PARPi resistance, as some BRCA wild-type PDAC remain sensitive to PARPi but resistant to platinum salts (Luo et al. 2015).

\section{Other gene mutations favoring PDAC development}

Germline mutations in genes coding for other members of the HR pathway have been associated with familial PDAC (Canto et al. 2013, Waddell et al. 2015, Zhen et al. 2015, Hu et al. 2016, Roberts et al. 2016). Germline BRCA1 mutations only account for a small proportion of familial PDAC, although the risk of developing PDAC in BRCA1 mutation carriers appears to be similar to that of BRCA2 mutation carriers (Ford et al. 1994, Thompson et al. 2002, Al-Sukhni et al. 2008, Vincent et al. 2011, Ryan et al. 2014, Neuzillet et al. 2015). The PALB2 (partner and localizer of BRCA2) protein binds to the BRCA1/2 proteins and ensures nuclear addressing (Zhang et al. 2009). Germline mutations in the PALB2 gene account for 2-3\% of familial PDAC (Jones et al. 2009, Tischkowitz et al. 2009, Slater et al. 2010, Peterlongo et al. 2011). Germline mutations in genes coding for ATM as well as genes encoding for other partners of the Fanconi DNA repair pathway (FANC-C and FANC-G) have also been associated with familial PDAC but are much rarer (van der Heijden et al. 2003, Couch et al. 2005, Roberts et al. 2016).

Interestingly, the marked sensitivity of PDAC to PARPi and DNA-damaging agents such as platinum salts is not specific to BRCA2 mutations but also applies to the

Table 1 Ongoing trials exploring the efficacy and toxicity of PARPi specifically in locally advanced and/or metastatic PDAC.

\begin{tabular}{|c|c|c|c|c|c|}
\hline Identifier & Drug & Phase & Arms & Inclusion criteria & Measured criteria \\
\hline NCT01296763 & Olaparib & Phase I & $\begin{array}{l}\text { Olaparib-irinotecan- } \\
\text { cisplatin-mitomycin C }\end{array}$ & $\begin{array}{l}\text { Stages III-IV, germline } B R C A 1 / 2 \\
\text { negative, first to second line }\end{array}$ & Dose-limiting toxicity, oS \\
\hline NCT02677038 & Olaparib & $\begin{array}{l}\text { Non-randomized } \\
\text { phase II }\end{array}$ & Olaparib & $\begin{array}{l}\text { Stage IV, second line, germline } \\
B R C A 1 / 2 \text { negative }\end{array}$ & ORR and AEs \\
\hline NCT02511223 & Olaparib & $\begin{array}{l}\text { Non-randomized } \\
\text { phase II }\end{array}$ & $\begin{array}{l}\text { Olaparib-irinotecan- } \\
\text { cisplatin-mitomycin C }\end{array}$ & $\begin{array}{l}\text { Stage IV, germline } B R C A 1 / 2 \\
\text { negative, first to second line }\end{array}$ & ORR, OS, PFS and AEs \\
\hline NCT02184195 & Olaparib & Phase III & Olaparib and placebo & $\begin{array}{l}\text { BRCA mutation, stage IV, no } \\
\text { progression after } 16 \text { weeks } \\
\text { of platinum }\end{array}$ & $\begin{array}{l}\text { PFS, OS, ORR, AEs and } \\
\text { QoL }\end{array}$ \\
\hline NCT02042378 & Rucaparib & $\begin{array}{l}\text { Non-randomized } \\
\text { phase II }\end{array}$ & Rucaparib & Second line, BRCA mutation & ORR, PFS, OS and AEs \\
\hline NCT01908478 & Veliparib & Phase I & Veliparib-gem-IMRT & Locally advanced or borderline & Dose-limiting toxicity, OS \\
\hline NCT01489865 & Veliparib & $\begin{array}{l}\text { Non-randomized } \\
\text { phase I-II }\end{array}$ & Veliparib-FOLFOX6 & $\begin{array}{l}\text { Stage IV, BRCA-associated } \\
\text { mutation }\end{array}$ & $\begin{array}{l}\text { Veliparib dosing, AEs } \\
\text { and ORR }\end{array}$ \\
\hline NCT01585805 & Veliparib & $\begin{array}{l}\text { Randomized } \\
\text { phase II }\end{array}$ & $\begin{array}{l}\text { Veliparib-gem-cis, } \\
\text { gem-cis and veliparib }\end{array}$ & $\begin{array}{l}B R C A 1 / 2 \text { or } P A L B 2 \text { mutation, } \\
\text { stage III-IV, second to third line }\end{array}$ & $\begin{array}{l}\text { Veliparib dosing, ORR, } \\
\text { AEs, OS, PFS and } \\
\text { genetic reversion of } \\
\text { BRCA mutations }\end{array}$ \\
\hline
\end{tabular}

AEs, adverse events; ORR, overall response rate; OS, overall survival; PFS, progression-free survival; QoL, quality of life. 
germline mutations of the other above-mentioned genes of the Fanconi pathway (Bryant et al. 2005, Farmer et al. 2005, van der Heijden et al. 2005, Villarroel et al. 2011).

Other genetic alterations in familial PDAC include germline $C D K N 2 A / p 16$ mutations, which are generally associated with atypical familial multiple-mole melanoma (FAMMM) syndrome, germline STK11 mutations observed in Peutz-Jeghers syndrome and germline PRSS1 mutations that are responsible for hereditary pancreatitis (Hruban et al. 2010, Vincent et al. 2011, Ryan et al. 2014, Neuzillet et al. 2015). In addition, patients with Lynch syndrome have a four- to eight-fold increased risk of developing PDAC compared with the general population.

\section{Concluding remarks}

BRCA2 mutation carriers who develop PDAC are a small and unique subset of patients with biological specificities. PDAC occurs in around 10\% of BRCA2-mutated families. Four to seven percent of sporadic PDAC and $10-17 \%$ of familial PDAC occur in relation to BRCA2 mutations, especially in the Jewish Ashkenazi population. Although this population is quite rare, there is unique opportunity for early diagnosis through screening and appropriate follow-up. However, the efficacy of EUS/MRI yearly screening has not yet been confirmed and the anxiety and cost of these investigations must be kept in mind. Future developments will probably include blood and urine markers.

Based on the understanding of the role of BRCA2 in HR, DNA-targeted chemotherapy (such as platinum salts) and radiation therapy, as well as inhibition of DNA repair (such as PARPi), offer promising therapeutic results with acceptable toxicity, although further evidence is needed on BRCA2-tailored treatment. Several PARPi are under investigation as monotherapy or in combination with cytotoxic agents.

Predicting the efficacy of these drugs is currently based on identification of germline $B R C A 2$ mutations (as well as $B R C A 1, P A L B 2$ or other HR-related genes), and research should continue to identify simpler and reproducible markers of HR deficiency and response to PARPi, such as immunohistochemistry, quick molecular testing on pathological samples or screening of circulating tumor cells or DNA. Next-generation sequencing will also help providing rapid assessment of $B R C A$ gene status.

Germline mutations in the above-mentioned genes account for less than $20 \%$ of all 'unstable phenotype' PDAC as determined by whole genome sequencing
(Waddell et al. 2015, Bailey et al. 2016). Thus, other PDAC germline mutations involving other DNA repair pathways may identify 'BRCA-like PDAC', which may also respond to platinum salts and PARPi. However, it is not known whether these treatments will benefit patients without germline but with somatic gene mutations. Better knowledge of the molecular alterations involved in this subset of PDAC tumors is essential to allow larger but more accurate patient selection for PARP inhibition.

Declaration of interest

$L M, J B, C N, V R$ and N S declared no competing interests. P H is a member of the advisory board with AstraZeneca in the POLO study.

\section{Funding}

This work did not receive any specific grant from any funding agency in the public, commercial or not-for-profit sector.

\section{Acknowledgements}

The authors thank Mrs Dale Roche-Lebrec for technical assistance in the preparation of the manuscript.

\section{References}

Al-Sukhni W, Rothenmund H, Borgida AE, Zogopoulos G, O'Shea A-M, Pollett A \& Gallinger S 2008 Germline BRCA1 mutations predispose to pancreatic adenocarcinoma. Human Genetics 124 271-278. (doi:10.1007/s00439-008-0554-0)

Andrei A-Z, Hall A, Smith AL, Bascuñana C, Malina A, Connor A, Altinel-Omeroglu G, Huang S, Pelletier J, Huntsman D, et al. 2015 Increased in vitro and in vivo sensitivity of BRCA2-associated pancreatic cancer to the poly(ADP-ribose) polymerase- $1 / 2$ inhibitor BMN 673. Cancer Letters 364 8-16. (doi:10.1016/j. canlet.2015.04.003)

Anglian Breast Cancer Study Group 2000 Prevalence and penetrance of BRCA1 and BRCA2 mutations in a population-based series of breast cancer cases. British Journal of Cancer 83 1301-1308. (doi:10.1054/ bjoc.2000.1407)

Bailey P, Chang DK, Nones K, Johns AL, Patch A-M, Gingras M-C, Miller DK, Christ AN, Bruxner TJC, Quinn MC, et al. 2016 Genomic analyses identify molecular subtypes of pancreatic cancer. Nature 531 47-52. (doi:10.1038/nature16965)

Bartsch DK, Slater EP, Carrato A, Ibrahim IS, Guillen-Ponce C, Vasen HFA, Matthäi E, Earl J, Jendryschek FS, Figiel J, et al. 2016 Refinement of screening for familial pancreatic cancer. Gut $\mathbf{6 5}$ 1314-1321. (doi:10.1136/gutjnl-2015-311098)

Bendell J, O'Reilly EM, Middleton MR, Chau I, Hochster H, Fielding A, Burke W \& Burris H 2015 Phase I study of olaparib plus gemcitabine in patients with advanced solid tumours and comparison with gemcitabine alone in patients with locally advanced/metastatic pancreatic cancer. Annals of Oncology 26 804-811. (doi:10.1093/ annonc/mdu581)

Breast Cancer Linkage Consortium 1999 Cancer risks in BRCA2 mutation carriers. Journal of the National Cancer Institute 91 1310-1316. (doi:10.1093/jnci/91.15.1310)
๑) 2016 Society for Endocrinology Printed in Great Britain
Published by Bioscientifica Ltd 
Breitkopf CR, Sinicrope PS, Rabe KG, Brockman TA, Patten CA, McWilliams RR, Ehlers S \& Petersen GM 2012 Factors influencing receptivity to future screening options for pancreatic cancer in those with and without pancreatic cancer family history. Hereditary Cancer in Clinical Practice 10 8. (doi:10.1186/1897-4287-10-8)

Brune KA, Lau B, Palmisano E, Canto M, Goggins MG, Hruban RH \& Klein AP 2010 Importance of age of onset in pancreatic cancer kindreds. Journal of the National Cancer Institute 102 119-126. (doi:10.1093/jnci/djp466)

Bryant HE, Schultz N, Thomas HD, Parker KM, Flower D, Lopez E, Kyle S, Meuth M, Curtin NJ \& Helleday T 2005 Specific killing of BRCA2-deficient tumours with inhibitors of poly(ADP-ribose) polymerase. Nature 434 913-917. (doi:10.1038/ nature03443)

Byrski T, Huzarski T, Dent R, Gronwald J, Zuziak D, Cybulski C, Kladny J, Gorski B, Lubinski J \& Narod SA 2009 Response to neoadjuvant therapy with cisplatin in BRCA1-positive breast cancer patients. Breast Cancer Research and Treatment 115 359-363. (doi:10.1007/s10549-008-0128-9)

Canto MI, Hruban RH, Fishman EK, Kamel IR, Schulick R, Zhang Z, Topazian M, Takahashi N, Fletcher J, Petersen G, et al. 2012 Frequent detection of pancreatic lesions in asymptomatic high-risk individuals. Gastroenterology 142 796-804. (doi:10.1053/j. gastro.2012.01.005

Canto MI, Harinck F, Hruban RH, Offerhaus GJ, Poley J-W, Kamel I, Nio Y, Schulick RS, Bassi C, Kluijt I, et al. 2013 International cancer of the pancreas screening (CAPS) consortium summit on the management of patients with increased risk for familial pancreatic cancer. Gut 62 339-347. (doi:10.1136/gutjnl-2012-303108)

Couch FJ, Johnson MR, Rabe K, Boardman L, McWilliams R, de Andrade M \& Petersen G 2005 Germ line Fanconi anemia complementation group $\mathrm{C}$ mutations and pancreatic cancer. Cancer Research 65 383-386.

Couch FJ, Johnson MR, Rabe KG, Brune K, de Andrade M, Goggins M, Rothenmund H, Gallinger S, Klein A, Petersen GM, et al. 2007 The prevalence of BRCA2 mutations in familial pancreatic cancer. Cancer Epidemiology, Biomarkers and Prevention 16 342-346. (doi:10.1158/1055-9965.EPI-06-0783)

Dhillon KK, Bajrami I, Taniguchi T \& Lord CJ 2016 Synthetic lethality: the road to novel therapies for breast cancer. Endocrine-Related Cancer 23 T39-T55. (doi:10.1530/ERC-16-0228)

Fam HK 2014 Delineating the effects BRCA1 and BRCA2 loss of heterozygosity in pancreatic cancer progression. Clinical Genetics $\mathbf{8 5}$ 18-20. (doi:10.1111/cge.12306)

Farmer H, McCabe N, Lord CJ, Tutt ANJ, Johnson DA, Richardson TB, Santarosa M, Dillon KJ, Hickson I, Knights C, et al. 2005 Targeting the DNA repair defect in BRCA mutant cells as a therapeutic strategy. Nature 434 917-921. (doi:10.1038/nature03445)

Ferrone CR, Levine DA, Tang LH, Allen PJ, Jarnagin W, Brennan MF, Offit K \& Robson ME 2008 BRCA germline mutations in jewish patients with pancreatic adenocarcinoma. Journal of Clinical Oncology 27 433-438. (doi:10.1200/JCO.2008.18.5546)

Fogelman DR, Wolff RA, Kopetz S, Javle M, Bradley C, Mok I, Cabanillas F \& Abbruzzese JL 2011 Evidence for the efficacy of Iniparib, a PARP-1 inhibitor, in BRCA2-associated pancreatic cancer. Anticancer Research 31 1417-1420.

Fogelman D, Sugar EA, Oliver G, Shah N, Klein A, Alewine C, Wang H, Javle M, Shroff R, Wolff RA, et al. 2015 Family history as a marker of platinum sensitivity in pancreatic adenocarcinoma. Cancer Chemotherapy and Pharmacology 76 489-498. (doi:10.1007/s00280015-2788-6)

Fong PC, Boss DS, Yap TA, Tutt A, Wu P, Mergui-Roelvink M, Mortimer P, Swaisland H, Lau A, O'Connor MJ, et al. 2009 Inhibition of poly(ADP-ribose) polymerase in tumors from BRCA mutation carriers. New England Journal of Medicine 361 123-134. (doi:10.1056/ NEJMoa0900212)
Ford D, Easton DF, Bishop DT, Narod SA \& Goldgar DE 1994 Risks of cancer in BRCA1-mutation carriers. Breast Cancer Linkage Consortium. Lancet 343 692-695. (doi:10.1016/S01406736(94)91578-4)

Fradet-Turcotte A, Sitz J, Grapton D \& Orthwein A 2016 BRCA2 functions: from DNA repair to replication fork stabilization. Endocrine-Related Cancer 23 T1-T17. (doi:10.1530/ERC-16-0297)

Gallagher DJ, Konner JA, Bell-McGuinn KM, Bhatia J, Sabbatini P, Aghajanian CA, Offit K, Barakat RR, Spriggs DR \& Kauff ND 2011 Survival in epithelial ovarian cancer: a multivariate analysis incorporating BRCA mutation status and platinum sensitivity. Annals of Oncology 22 1127-1132. (doi:10.1093/annonc/mdq577)

Goggins M, Schutte M, Lu J, Moskaluk CA, Weinstein CL, Petersen GM, Yeo CJ, Jackson CE, Lynch HT, Hruban RH, et al. 1996 Germline BRCA2 gene mutations in patients with apparently sporadic pancreatic carcinomas. Cancer Research 56 5360-5364.

Golan T, Kanji ZS, Epelbaum R, Devaud N, Dagan E, Holter S, Aderka D, Paluch-Shimon S, Kaufman B, Gershoni-Baruch R, et al. 2014 Overall survival and clinical characteristics of pancreatic cancer in BRCA mutation carriers. British Journal of Cancer 111 1132-1138. (doi:10.1038/bjc.2014.418)

Gooiker GA, Lemmens VEPP, Besselink MG, Busch OR, Bonsing BA, Molenaar IQ, Tollenaar RA, de Hingh IHJT \& Wouters MWJM 2014 Impact of centralization of pancreatic cancer surgery on resection rates and survival. British Journal of Surgery 101 1000-1005. (doi:10.1002/bjs.9468)

Hahn SA, Greenhalf B, Ellis I, Sina-Frey M, Rieder H, Korte B, Gerdes B, Kress R, Ziegler A, Raeburn JA, et al. 2003 BRCA2 germline mutations in familial pancreatic carcinoma. Journal of the National Cancer Institute 95 214-221. (doi:10.1093/jnci/95.3.214)

Hay T, Matthews JR, Pietzka L, Lau A, Cranston A, Nygren AOH, Douglas-Jones A, Smith GCM, Martin NMB, O'Connor M, et al. 2009 Poly(ADP-ribose) polymerase-1 inhibitor treatment regresses autochthonous Brca2/p53-mutant mammary tumors in vivo and delays tumor relapse in combination with carboplatin. Cancer Research 69 3850-3855. (doi:10.1158/0008-5472.CAN-08-2388)

Holloman WK 2011 Unraveling the mechanism of BRCA2 in homologous recombination. Nature Structural \& Molecular Biology 18 748-754. (doi:10.1038/nsmb.2096)

Holter S, Borgida A, Dodd A, Grant R, Semotiuk K, Hedley D, Dhani N, Narod S, Akbari M, Moore M, et al. 2015 Germline BRCA mutations in a large clinic-based cohort of patients with pancreatic adenocarcinoma. Journal of Clinical Oncology 33 3124-3129. (doi:10.1200/JCO.2014.59.7401)

Hruban RH, Canto MI, Goggins M, Schulick R \& Klein AP 2010 Update on familial pancreatic cancer. Advances in Surgery 44 293-311. (doi:10.1016/j.yasu.2010.05.011)

Hu C, Hart SN, Bamlet WR, Moore RM, Nandakumar K, Eckloff BW, Lee YK, Petersen GM, McWilliams RR \& Couch FJ 2016 Prevalence of pathogenic mutations in cancer predisposition genes among pancreatic cancer patients. Cancer Epidemiology, Biomarkers \& Prevention 25 207-211. (doi:10.1158/1055-9965.epi-15-0455)

Iqbal J, Ragone A, Lubinski J, Lynch HT, Moller P, Ghadirian P, Foulkes WD, Armel S, Eisen A, Neuhausen SL, et al. 2012 The incidence of pancreatic cancer in BRCA1 and BRCA2 mutation carriers. British Journal of Cancer 107 2005-2009. (doi:10.1038/ bjc.2012.483)

Jacob DA, Bahra M, Langrehr JM, Boas-Knoop S, Stefaniak R, Davis J, Schumacher G, Lippert S \& Neumann UP 2007 Combination therapy of poly (ADP-ribose) polymerase inhibitor 3-aminobenzamide and gemcitabine shows strong antitumor activity in pancreatic cancer cells. Journal of Gastroenterology and Hepatology 22 738-748. (doi:10.1111/j.1440-1746.2006.04496.x)

Jones S, Hruban RH, Kamiyama M, Borges M, Zhang X, Parsons DW, Lin JC-H, Palmisano E, Brune K, Jaffee EM, et al. 2009 Exomic 
sequencing identifies PALB2 as a pancreatic cancer susceptibility gene. Science 324 217-217. (doi:10.1126/science.1171202)

Kaufman B, Shapira-Frommer R, Schmutzler RK, Audeh MW, Friedlander M, Balmana J, Mitchell G, Fried G, Stemmer SM, Hubert A, et al. 2015 Olaparib monotherapy in patients with advanced cancer and a germline BRCA1/2 mutation. Journal of Clinical Oncology 33 244-250. (doi:10.1200/JCO.2014. 56.2728)

Kaye SB, Lubinski J, Matulonis U, Ang JE, Gourley C, Karlan BY, Amnon A, Bell-McGuinn KM, Chen L-M, Friedlander M, et al. 2012 Phase II, open-label, randomized, multicenter study comparing the efficacy and safety of olaparib, a poly (ADP-ribose) polymerase inhibitor, and pegylated liposomal doxorubicin in patients with BRCA1 or BRCA2 mutations and recurrent ovarian cancer. Journal of Clinical Oncology 30 372-379. (doi:10.1200/ JCO.2011.36.9215)

Kim DH, Crawford B, Ziegler J \& Beattie MS 2009 Prevalence and characteristics of pancreatic cancer in families with BRCA1 and BRCA2 mutations. Familial Cancer 8 153-158. (doi:10.1007/s10689008-9220-x)

Klapman J \& Malafa MP 2008 Early detection of pancreatic cancer: why, who, and how to screen. Cancer Control 15 280-287.

Klein AP 2012 Genetic susceptibility to pancreatic cancer. Molecular Carcinogenesis 51 14-24. (doi:10.1002/mc.20855)

Klein AP, Brune KA, Petersen GM, Goggins M, Tersmette AC, Offerhaus GJA, Griffin C, Cameron JL, Yeo CJ, Kern S, et al. 2004 Prospective risk of pancreatic cancer in familial pancreatic cancer kindreds. Cancer Research 64 2634-2638. (doi:10.1158/0008-5472. CAN-03-3823)

Langer P, Kann PH, Fendrich V, Habbe N, Schneider M, Sina M, Slater EP, Heverhagen JT, Gress TM, Rothmund M, et al. 2009 Five years of prospective screening of high-risk individuals from families with familial pancreatic cancer. Gut 58 1410-1418. (doi:10.1136/ gut.2008.171611)

Lee H 2014 Cycling with BRCA2 from DNA repair to mitosis. Experimental Cell Research 329 78-84. (doi:10.1016/j. yexcr.2014.10.008)

Lee J-M, Ledermann JA \& Kohn EC 2014 PARP inhibitors for BRCA1/2 mutation-associated and BRCA-like malignancies. Annals of Oncology 25 32-40. (doi:10.1093/annonc/mdt384)

Lohse I, Borgida A, Cao P, Cheung M, Pintilie M, Bianco T, Holter S, Ibrahimov E, Kumareswaran R, Bristow RG, et al. 2015 BRCA1 and BRCA2 mutations sensitize to chemotherapy in patient-derived pancreatic cancer xenografts. British Journal of Cancer 113 425-432. (doi:10.1038/bjc.2015.220)

Lowery MA, Kelsen DP, Stadler ZK, Yu KH, Janjigian YY, Ludwig E, D'Adamo DR, Salo-Mullen E, Robson ME, Allen PJ, et al. 2011 An emerging entity: pancreatic adenocarcinoma associated with a known BRCA mutation: clinical descriptors, treatment implications, and future directions. Oncologist 16 1397-1402. (doi:10.1634/ theoncologist.2011-0185)

Lu C 2015 Screening for pancreatic cancer in familial high-risk individuals: a systematic review. World Journal of Gastroenterology 21 8678. (doi:10.3748/wjg.v21.i28.8678)

Lucas AL, Shakya R, Lipsyc MD, Mitchel EB, Kumar S, Hwang C, Deng L, Devoe C, Chabot JA, Szabolcs M, et al. 2013 High prevalence of BRCA1 and BRCA2 germline mutations with loss of heterozygosity in a series of resected pancreatic adenocarcinoma and other neoplastic lesions. Clinical Cancer Research 19 3396-3403. (doi:10.1158/1078-0432.CCR-12-3020)

Lucas AL, Frado LE, Hwang C, Kumar S, Khanna LG, Levinson EJ, Chabot JA, Chung WK \& Frucht H 2014 BRCA1 and BRCA2 germline mutations are frequently demonstrated in both high-risk pancreatic cancer screening and pancreatic cancer cohorts: BRCA1/2 germline mutations in pancreatic cancer. Cancer 120 1960-1967. (doi:10.1002/ cncr.28662)
Ludwig E, Olson SH, Bayuga S, Simon J, Schattner MA, Gerdes H, Allen PJ, Jarnagin WR \& Kurtz RC 2011 Feasibility and yield of screening in relatives from familial pancreatic cancer families. American Journal of Gastroenterology 106 946-954. (doi:10.1038/ ajg.2011.65)

Luo G, Lu Y, Jin K, Cheng H, Guo M, Liu Z, Long J, Liu C, Ni Q \& Yu X 2015 Pancreatic cancer: BRCA mutation and personalized treatment. Expert Review of Anticancer Therapy 15 1223-1231. (doi:10.1586/ 14737140.2015.1086271)

Matthaei H, Schulick RD, Hruban RH \& Maitra A 2011 Cystic precursors to invasive pancreatic cancer. Nature Reviews. Gastroenterology \& Hepatology 8 141-150. (doi:10.1038/nrgastro.2011.2)

Moynahan ME, Pierce AJ \& Jasin M 2001 BRCA2 is required for homology-directed repair of chromosomal breaks. Molecular Cell 7 263-272. (doi:10.1016/S1097-2765(01)00174-5)

Murai J, Huang SN, Das BB, Renaud A, Zhang Y, Doroshow JH, Ji J, Takeda S \& Pommier Y 2012 Trapping of PARP1 and PARP2 by clinical PARP inhibitors. Cancer Research 72 5588-5599. (doi:10.1158/0008-5472.CAN-12-2753)

Murphy KM, Brune KA, Griffin C, Sollenberger JE, Petersen GM Bansal R, Hruban RH \& Kern SE 2002 Evaluation of candidate genes MAP2K4, MADH4, ACVR1B, and BRCA2 in familial pancreatic cancer deleterious BRCA2 mutations in 17\%. Cancer Research 62 3789-3793.

Neuzillet C, de Gramont A, Tijeras-Raballand A, de Mestier L, Cros J, Faivre S \& Raymond E 2014 Perspectives of TGF- $\beta$ inhibition in pancreatic and hepatocellular carcinomas. Oncotarget 578. (doi:10.18632/oncotarget.1569)

Neuzillet C, Tijeras-Raballand A, Bourget P, Cros J, Couvelard A, Sauvanet A, Vullierme M-P, Tournigand C \& Hammel P 2015 State of the art and future directions of pancreatic ductal adenocarcinoma therapy. Pharmacology \& Therapeutics 155 80-104. (doi:10.1016/j. pharmthera.2015.08.006)

Ozçelik H, Schmocker B, Di Nicola N, Shi XH, Langer B, Moore M, Taylor BR, Narod SA, Darlington G, Andrulis IL, et al. 1997 Germline BRCA2 6174delT mutations in Ashkenazi Jewish pancreatic cancer patients. Nature Genetics 16 17-18. (doi:10.1038/ng0597-17)

Peterlongo P, Catucci I, Pasquini G, Verderio P, Peissel B, Barile M, Varesco L, Riboni M, Fortuzzi S, Manoukian S, et al. 2011 PALB2 germline mutations in familial breast cancer cases with personal and family history of pancreatic cancer. Breast Cancer Research and Treatment 126 825-828. (doi:10.1007/s10549010-1305-1)

Porcelli L, Quatrale AE, Mantuano P, Leo MG, Silvestris N, Rolland JF, Carioggia E, Lioce M, Paradiso A \& Azzariti A 2013 Optimize radiochemotherapy in pancreatic cancer: PARP inhibitors a new therapeutic opportunity. Molecular Oncology 7 308-322. (doi:10.1016/j.molonc.2012.10.002)

Rahib L, Smith BD, Aizenberg R, Rosenzweig AB, Fleshman JM \& Matrisian LM 2014 Projecting cancer incidence and deaths to 2030: the unexpected burden of thyroid, liver, and pancreas cancers in the United States. Cancer Research 74 2913-2921. (doi:10.1158/00085472.CAN-14-0155)

Raimondi S, Maisonneuve P \& Lowenfels AB 2009 Epidemiology of pancreatic cancer: an overview. Nature Reviews. Gastroenterology \& Hepatology 6 699-708. (doi:10.1038/nrgastro.2009.177)

Roberts NJ, Norris AL, Petersen GM, Bondy ML, Brand R, Gallinger S, Kurtz RC, Olson SH, Rustgi AK, Schwartz AG, et al. 2016 Whole genome sequencing defines the genetic heterogeneity of familial pancreatic cancer. Cancer Discovery 6 166-175. (doi:10.1158/21598290.CD-15-0402)

Rowley M, Ohashi A, Mondal G, Mills L, Yang L, Zhang L, Sundsbak R, Shapiro V, Muders MH, Smyrk T, et al. 2011 Inactivation of Brca2 promotes Trp53-associated but inhibits KrasG12D-dependent pancreatic cancer development in mice. Gastroenterology 140 1303-1313.e1-e3. (doi:10.1053/j.gastro.2010.12.039) http://erc.endocrinology-journals.org

DOI: 10.1530/ERC-16-0269
(C) 2016 Society for Endocrinology Printed in Great Britain 
Ryan DP, Hong TS \& Bardeesy N 2014 Pancreatic adenocarcinoma New England Journal of Medicine 371 1039-1049. (doi:10.1056/ NEJMra1404198)

Sakai W, Swisher EM, Karlan BY, Agarwal MK, Higgins J, Friedman C, Villegas E, Jacquemont C, Farrugia DJ, Couch FJ, et al. 2008 Secondary mutations as a mechanism of cisplatin resistance in BRCA2-mutated cancers. Nature 451 1116-1120. (doi:10.1038/nature06633)

Salo-Mullen EE, O'Reilly EM, Kelsen DP, Ashraf AM, Lowery MA, Yu KH, Reidy DL, Epstein AS, Lincoln A, Saldia A, et al. 2015 Identification of germline genetic mutations in patients with pancreatic cancer: germline mutations in pancreatic cancer. Cancer 121 4382-4388. (doi:10.1002/cncr.29664)

Sandhu SK, Yap TA \& de Bono JS 2010 Poly(ADP-ribose) polymerase inhibitors in cancer treatment: a clinical perspective. European Journal of Cancer 46 9-20. (doi:10.1016/j.ejca.2009.10.021)

Shi C, Klein AP, Goggins M, Maitra A, Canto M, Ali S, Schulick R, Palmisano E \& Hruban RH 2009 Increased prevalence of precursor lesions in familial pancreatic cancer patients. Clinical Cancer Research 15 7737-7743. (doi:10.1158/1078-0432.CCR-09-0004)

Siegel RL, Miller KD \& Jemal A 2016 Cancer statistics, 2016. CA: A Cancer Journal for Clinicians 66 7-30. (doi:10.3322/caac.21332)

Skoulidis F, Cassidy LD, Pisupati V, Jonasson JG, Bjarnason H, Eyfjord JE, Karreth FA, Lim M, Barber LM, Clatworthy SA, et al. 2010 Germline Brca2 heterozygosity promotes Kras(G12D) -driven carcinogenesis in a murine model of familial pancreatic cancer. Cancer Cell $\mathbf{1 8}$ 499-509. (doi:10.1016/j.ccr.2010.10.015)

Slater EP, Langer P, Niemczyk E, Strauch K, Butler J, Habbe N, Neoptolemos JP, Greenhalf W \& Bartsch DK 2010 PALB2 mutations in European familial pancreatic cancer families. Clinical Genetics $\mathbf{7 8}$ 490-494. (doi:10.1111/j.1399-0004.2010.01425.x)

Sonnenblick A, Kadouri L, Appelbaum L, Peretz T, Sagi M, Goldberg Y \& Hubert A 2011 Complete remission, in BRCA2 mutation carrier with metastatic pancreatic adenocarcinoma, treated with cisplatin based therapy. Cancer Biology \& Therapy 12 165-168. (doi:10.4161/ cbt.12.3.16292)

Tanaka M, Fernández-del Castillo C, Adsay V, Chari S, Falconi M, Jang J-Y, Kimura W, Levy P, Pitman MB, Schmidt CM, et al. 2012 International consensus guidelines 2012 for the management of IPMN and MCN of the pancreas. Pancreatology 12 183-197. (doi:10.1016/j.pan.2012.04.004)

Thompson LH 2005 Unraveling the Fanconi anemia-DNA repair connection. Nature Genetics 37 921-922. (doi:10.1038/ng0905-921)

Thompson D, Easton DF \& Breast Cancer Linkage Consortium 2002 Cancer incidence in BRCA1 mutation carriers. Journal of the National Cancer Institute 94 1358-1365. (doi:10.1093/jnci/94.18.1358)

Thorslund T \& West SC 2007 BRCA2: a universal recombinase regulator Oncogene 26 7720-7730. (doi:10.1038/sj.onc.1210870)

Tischkowitz MD, Sabbaghian N, Hamel N, Borgida A, Rosner C, Taherian N, Srivastava A, Holter S, Rothenmund H, Ghadirian P, et al. 2009 Analysis of the gene coding for the BRCA2-interacting protein PALB2 in familial and sporadic pancreatic cancer. Gastroenterology 137 1183-1186. (doi:10.1053/j.gastro.2009.06.055) van Asperen CJ 2005 Cancer risks in BRCA2 families: estimates for sites other than breast and ovary. Journal of Medical Genetics 42 711-719. (doi:10.1136/jmg.2004.028829)

van der Heijden MS, Yeo CJ, Hruban RH \& Kern SE 2003 Fanconi anemia gene mutations in young-onset pancreatic cancer. Cancer Research 63 2585-2588.

van der Heijden MS, Brody JR, Dezentje DA, Gallmeier E, Cunningham SC, Swartz MJ, DeMarzo AM, Offerhaus GJA, Isacoff $\mathrm{WH}$, Hruban RH, et al. 2005 In vivo therapeutic responses contingent on Fanconi anemia/BRCA2 status of the tumor. Clinical Cancer Research 11 7508-7515. (doi:10.1158/1078-0432. CCR-05-1048)

Vasen H, Ibrahim I, Ponce CG, Slater EP, Matthäi E, Carrato A, Earl J, Robbers K, van Mil AM, Potjer T, et al. 2016 Benefit of surveillance for pancreatic cancer in high-risk individuals: outcome of long-term prospective follow-up studies from three european expert centers. Journal of Clinical Oncology 34 2010-2019. (doi:10.1200/ JCO.2015.64.0730)

Villarroel MC, Rajeshkumar NV, Garrido-Laguna I, De Jesus-Acosta A, Jones S, Maitra A, Hruban RH, Eshleman JR, Klein A, Laheru D, et al. 2011 Personalizing cancer treatment in the age of global genomic analyses: PALB2 gene mutations and the response to DNA damaging agents in pancreatic cancer. Molecular Cancer Therapeutics 10 3-8. (doi:10.1158/1535-7163.MCT-10-0893)

Vincent A, Herman J, Schulick R, Hruban RH \& Goggins M 2011 Pancreatic cancer. Lancet 378 607-620. (doi:10.1016/S01406736(10)62307-0)

Vyas O, Leung K, Ledbetter L, Kaley K, Rodriguez T, Garcon MC \& Saif MW 2015 Clinical outcomes in pancreatic adenocarcinoma associated with BRCA-2 mutation. Anti-Cancer Drugs 26 224-226. (doi:10.1097/CAD.0000000000000178)

Waddell N, Pajic M, Patch A-M, Chang DK, Kassahn KS, Bailey P, Johns AL, Miller D, Nones K, Quek K, et al. 2015 Whole genomes redefine the mutational landscape of pancreatic cancer. Nature $\mathbf{5 1 8}$ 495-501. (doi:10.1038/nature14169)

Wang L, Brune KA, Visvanathan K, Laheru D, Herman J, Wolfgang C, Schulick R, Cameron JL, Goggins M, Hruban RH, et al. 2009 Elevated cancer mortality in the relatives of patients with pancreatic cancer. Cancer Epidemiology, Biomarkers \& Prevention 18 2829-2834. (doi:10.1158/1055-9965.epi-09-0557)

Yap TA, Sandhu SK, Carden CP \& de Bono JS 2011 Poly(ADP-ribose) polymerase (PARP) inhibitors: exploiting a synthetic lethal strategy in the clinic. CA: A Cancer Journal for Clinicians 61 31-49. (doi:10.3322/caac.20095)

Zhang F, Ma J, Wu J, Ye L, Cai H, Xia B \& Yu X 2009 PALB2 links BRCA1 and BRCA2 in the DNA-damage response. Current Biology 19 524-529. (doi:10.1016/j.cub.2009.02.018)

Zhen DB, Rabe KG, Gallinger S, Syngal S, Schwartz AG, Goggins MG, Hruban RH, Cote ML, McWilliams RR, Roberts NJ, et al. 2015 BRCA1, BRCA2, PALB2, and CDKN2A mutations in familial pancreatic cancer: a PACGENE study. Genetics in Medicine $\mathbf{1 7}$ 569-577. (doi:10.1038/gim.2014.153)

Received in final form 6 August 2016

Accepted 10 August 2016

Accepted Preprint published online 10 August 2016
(C) 2016 Society for Endocrinology Printed in Great Britain
Published by Bioscientifica Ltd 